\title{
KITH AND KIN
}

\author{
Alexander Graham Bell \\ Washington, D. C.
}

$I^{N}$ N DEALING with genealogical subjects I am much surprised at the poverty of the English language in words expressive of relationship.

We have no term to express generally the relation of one member of a family to another irrespective of sex. We speak of "brothers and sisters" but have no common term for the relationship intended, unless the rather clumsy word "siblings" recently proposed should become generally adopted.

We have no general term, irrespective of sex, for the relationship indicated by the words "uncle- and aunt," nor have we any other word than "cousin" to express collateral relationship, and we use the term in the most vague way.

It is surely advisable, in dealing with genealogical subjects, to adopt a terminology that shall be clear, distinct and unambiguous.

I have hitherto employed a plan of designating the ancestors of an individual by numbers $(2,3,4,5,6$, etc.), even numbers representing males and odd numbers females (see Journal of Heredity for May 1921). While this method meets the wants of a scientific classification of ancestry, it does not fulfil the need for an ordinary terminology.

We of ten allude to our "kith and kin." We all have a pretty definite idea of what we mean by "kin,"relationship through a common ancestor, our own kindred, our blood relatives; but what do we mean by "kith?" The word by itself is obsolete. Webster defines it as "acquaintance, intimate acquaintance and relationship."

I think it would be a good plan to revive the term "kith" and give it the special meaning of relationship through a common descendant.
Kin:-Persons who have a common ancestor are kin.

Kith:-Persons who have a common descendant would be kith.

The following diagrams illustrate the proposed terminology. KIN (Fig. 1)

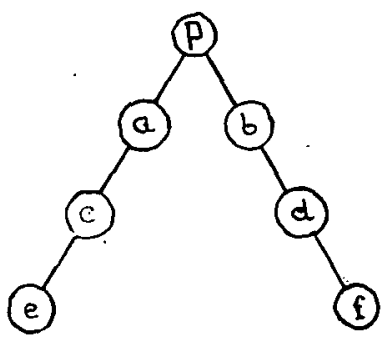

Kin:-All the descendants of the propositus $P$ in the above diagram are kin to one another. $a$ and $b$ are first kin, $c$ and $d$ are second kin, $e$ and $f$ are third kin, and so on.

Under this terminology the members of a family (brothers and sisters) are first kin to one another by virtue of the possession of a common parent (either father or mother). Where the brothers or sisters, $\left(\begin{array}{ll}a & b\end{array}\right)$ have the same father and mother they are doubly first kin to one another: or, perhaps, it would be better to say they are full kin, because all of their ancestors are the same in each case.

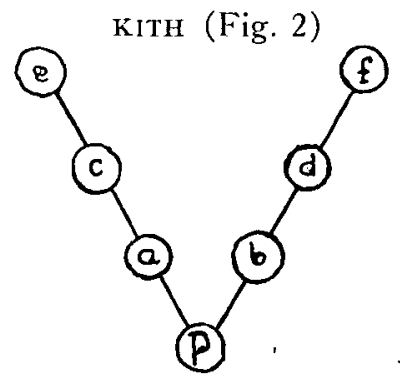

Kith:-All the ancestors of the propositus $P$ in this second diagram are kith to one another. $a$ and $b$ are 
first kith, $c$ and $d$ second kith, $e$ and $f$ third kith, etc.

Under this terminology husband and wife become first kith when they have a child, $P$. All of the four grandparents of the child $P$ would be second kith, the eight great-grandparents would be third kith, the sixteen greatgrandparents fourth kith, etc.

The word "kith" would thus mean more than mere "acquaintance." It would indicate a sort of indirect blood relationship. In the case of persons who are kith their blood mingles in their common descendant.

These definitions of kith and kin seem to me to be satisfactory as far as they are used to express the relationship of persons belonging to the same generation. The case changes, however, when you are dealing with persons in different generations, as "uncle and nephew," "first cousin once removed" etc. In such cases it may be necessary to specify the individual degree of relationship to the common ancestor or descendant. For example, uncle and nephew, $a$ and $d$ Fig. 1, are first and second kin through the common ancestor $P$, and first cousins once removed, $c$ and $f$ are second and third kin through the common ancestor $P$.

In the case of persons who are kith it would be the same thing reversed, the blood relationship would be through a common descendant. In Fig. 2, $a$ and $f$ would be first and third kith through the common descendant $P$, a relationship for which there is at present no name whatever.

Our terms for ancestors and descendants are also very clumsy and become impracticable of use when we get a few generations from the individual studied. The relation of ancestors is more quickly apparent if we speak of first parents, second parents, third parents, fourth parents, etc., than if we say parents, grandparents, great-grandparents, great-great-grandparents. The advantage is more and more obvious the farther we go from the propositus, $P$; for it is certainly simpler to speak of his sixth parents than of his greatgreat-great-great-grandparents.

The same terms could be used for descendants and instead of speaking of children, grandchildren and greatgrandchildrèn we could say first children, second children and third children.

In a subject of such general interest as this it seems to me important that the terminology should be easily understood, and I hope that these suggestions will be of use in starting a discussion of the whole subject.

\section{Foundations of Human Genetics}

Grundriss der Menschlichen ErbLICHKEITSLEHRE UND RASSEN*Hygiene, Band I, Menschliche Erblichkeitslehre, von Prof. Dr. Erwin Baur, Prof. Dr. Eugen Fischer, u. Dr. Fritz Lenz. Mit 65 fig. im Text. J. F. Lehmanns Verlag, Muenchen, 1921, pp. 305.

Three scholars of recognized standing have united to put out this comprehensive work on eugenics and social hygiene. In the present volume Dr. Baur outlines the general principles of heredity and variation in the first part, while Dr. Fischer in the second part discusses racial differences in mankind.
The third and fourth parts, by Dr. Lenz, are respectively devoted to the inheritance of tendencies to disease, and to the inheritance of mental traits. It is stated that the concluding volume, not yet published, will be entirely the work of Dr. Lenz, and will be devoted to "race hygiene." The present volume, which is compiled principally from continental sources, gives a good general picture of the subject. Dr. Fischer and Dr. Lenz confine themselves mainly to stating that certain traits are inherited, without discussing in detail the manner of inheritance.-P. P. 